\title{
PASSIVE COOLING OF BUILDINGS
}

Ath. Argiriou

Dept. of Physics, University of Patras 


\section{PAsSIVE COOLING}

- The world trade in A/C equipment has been tripled during the last decade.

-Ammul purchases of $\mathrm{A} / \mathrm{C}$ in Durope has been inereased tremedeously, (800 Per Cent In Greece)

-The use of A/C ereates important problems of peak electricity load, (23\% in USA)

-The use CrC's ereates environmental problems

-The use of $\mathrm{A} / \mathrm{C}$ creates indoor air quality problems

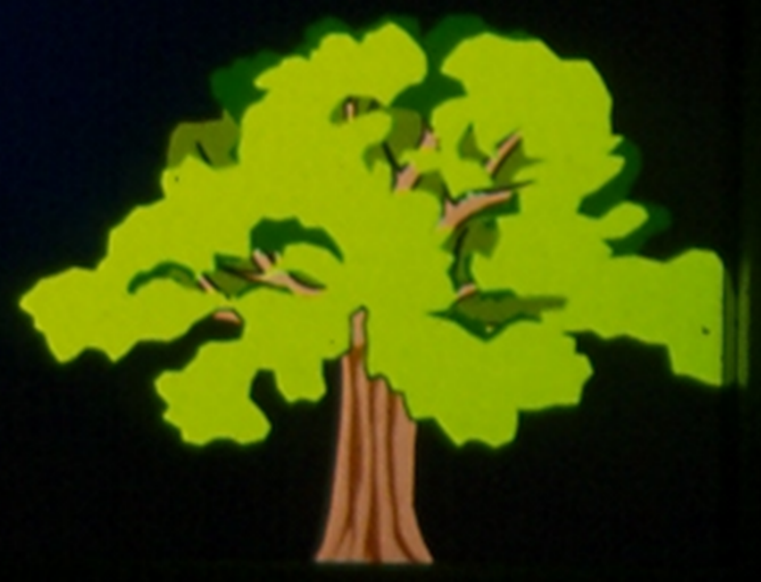




\section{PASSIVE COOLING}

\section{数}

- FRAMEWORK FOR CONSIDERING PASSIVE COOLING

Landscaping, Building form, Layout and External Finishings, Solar Control, Thermal Insulation, Control of Internal Gains

2. MODULATION OF HEAT GAINS : Use of the thermal capacity of the building.

3. HEAT DISSIPATION : Rejection of the excess heat to an environmental heat sink, (Evaporative, Convective, Ground) 


\section{PASSIVE COOLING}

Fiticient solar control of extemal transparent

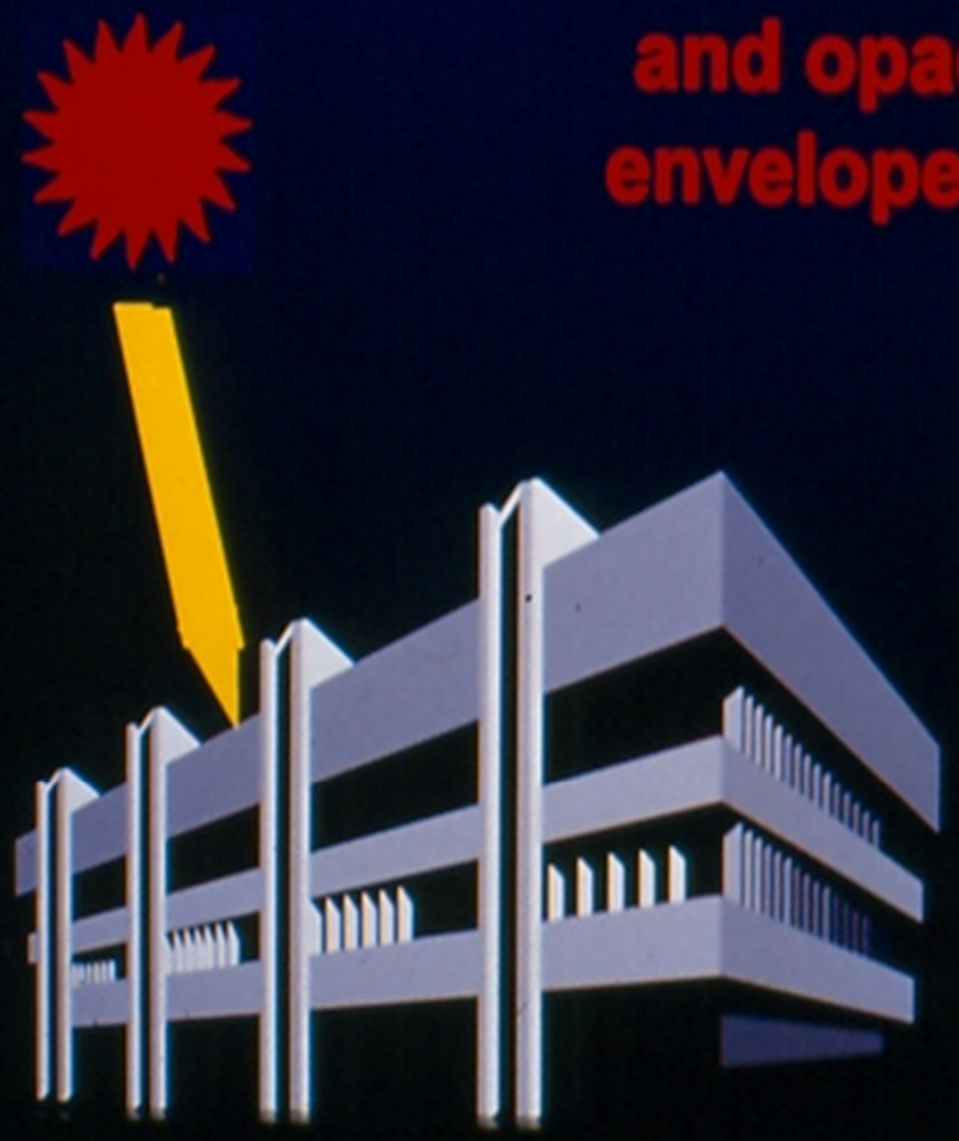

Shading can be achieved using trees and natural vegetation, neighbouring buildings, and fixed or mobile shading elements attached on the building's envelope. 


\section{PASSIVE COOLING}

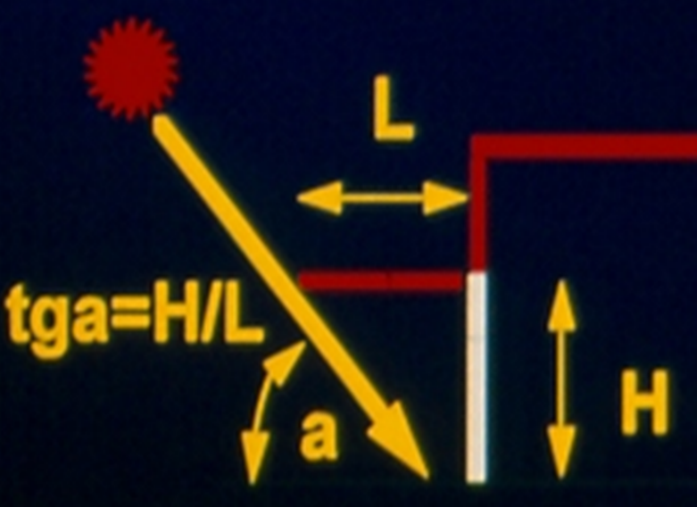

Fixed or movable external shading devices like overhangs, offer efiicient solar control to direct solar radiation.

However, the effect of diffuse and ground reflected radiation should be taken into account.

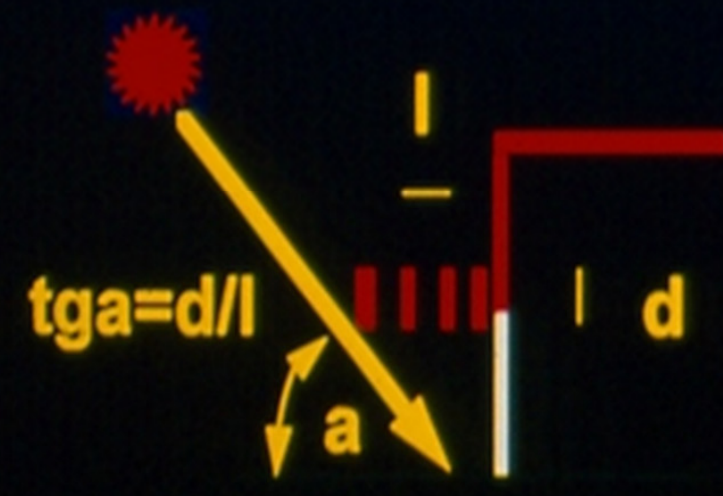

Design of the external shading devices should be based on the optimisation of

the heating, cooling and lighting performance of the building 


\section{PASSIVE COOLING}

Internal shading devices are less efiicient than the external because solar radiation enters

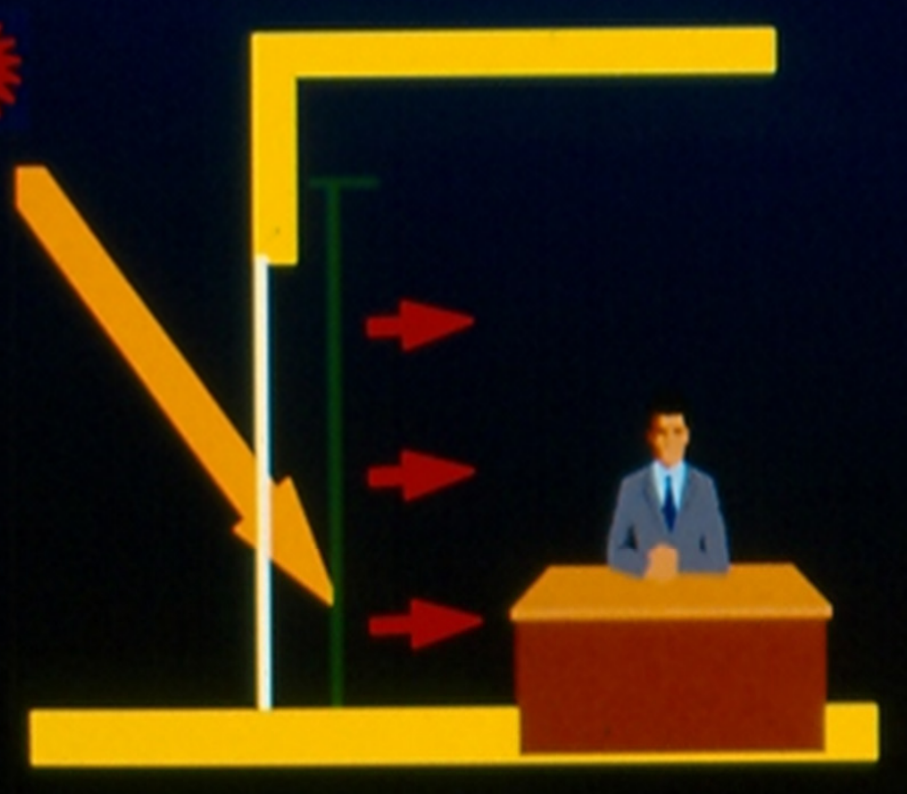
partly to the building.

Internal shading devices should permit natural ventilation and transmission of daylight.

A combination of external and internal shading devices can Ofier efilicient solar control. 


\section{PASSIVE COOLING}

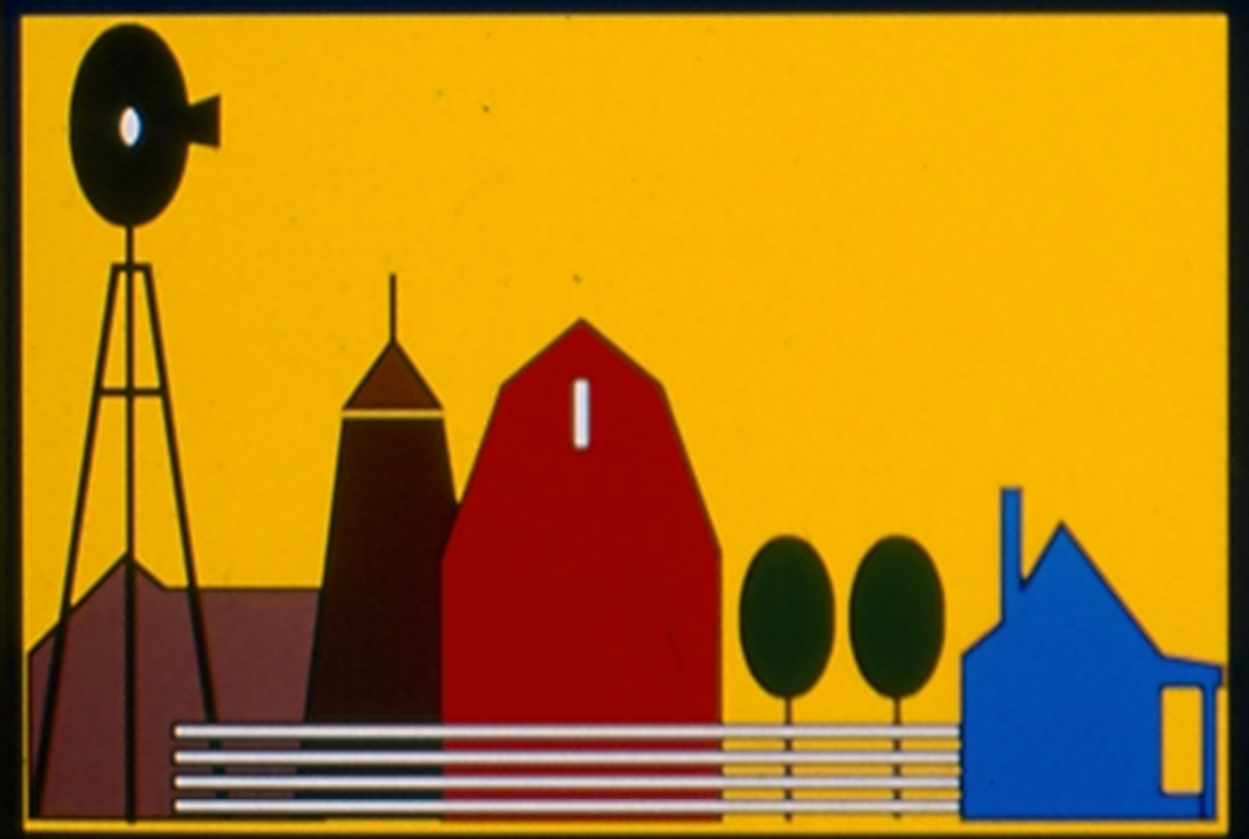

Modifications of microclimate around buildings can help to improve indoor comfort conditions and to reduce cooling loads, while also providing protected spaces for outdoor use.

Appropriate siting of a building can provide natural solar protection and help to take advantage of local winds 


\section{PASSIVE COOLING}
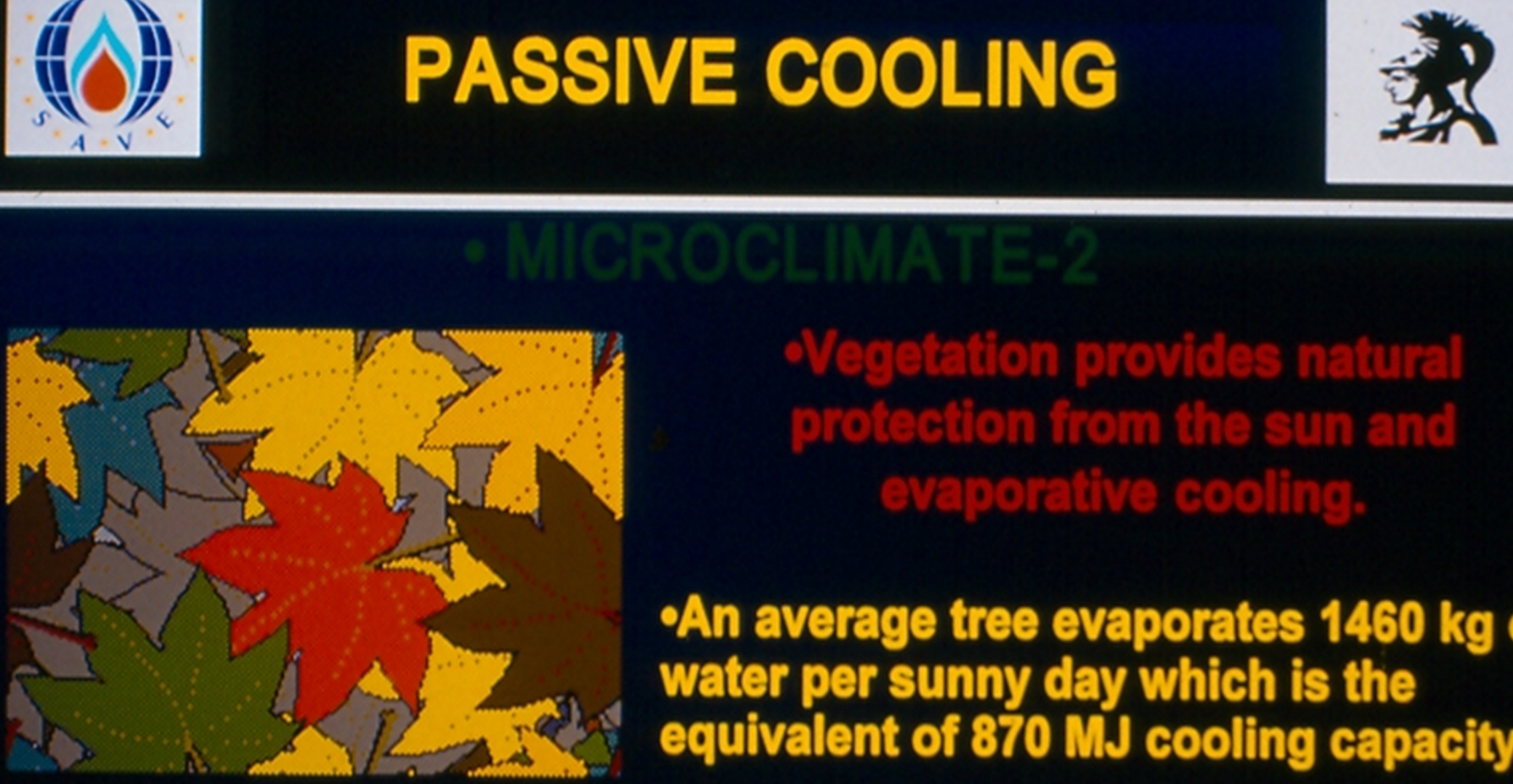

-Vegetation provides natural protection from the sun and evaporative cooling.

-An average tree evaporates $1460 \mathrm{~kg}$ of water per sunny day which is the equivalent of $870 \mathrm{MJ}$ cooling capacity,

-Evapotranspiration from one tree can save 1-2.4 MJ of electricity in AC per year.

- Latent heat transfer from wet grass can result in temperature 6-8 C cooler than exposed soil and one acre of grass can trasfer more than 50 GJ per day 


\section{PASSIVE COOLING}
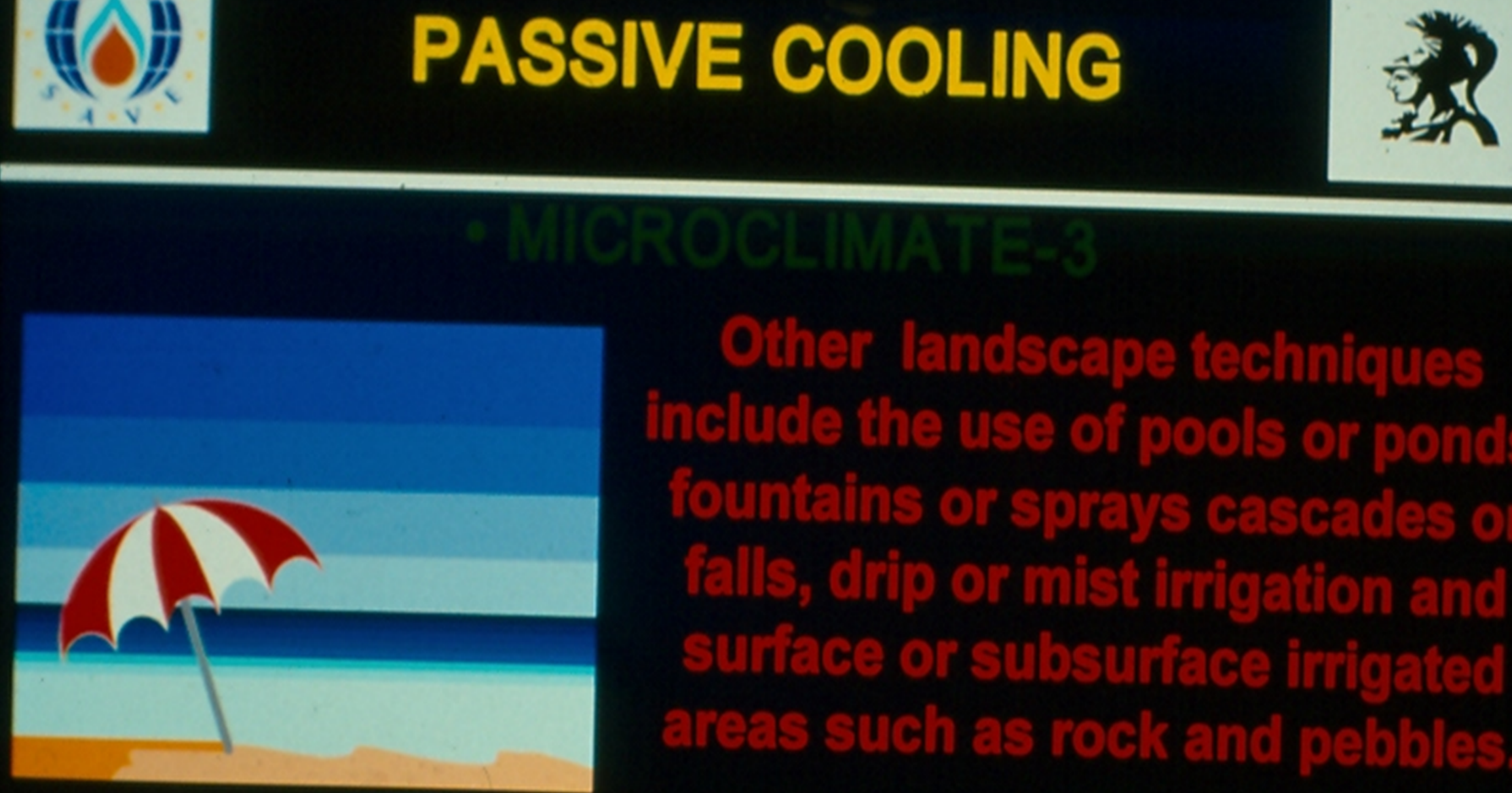

Other landscape techniques include the use of pools or ponds, fountains or sprays cascades or falls, drip or mist irrigation and surface or subsurface irrigated areas such as rock and pebbles.

- Under mean conditions of wind speed, dry and wet bulb temperatures, the energy released by a square meter of open water surface is close to 200 Joules. 


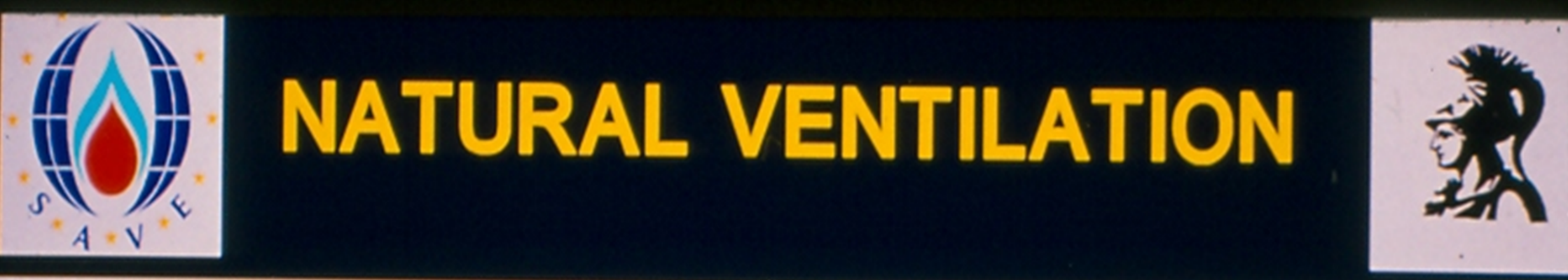

\section{-WIND PRESSURE}

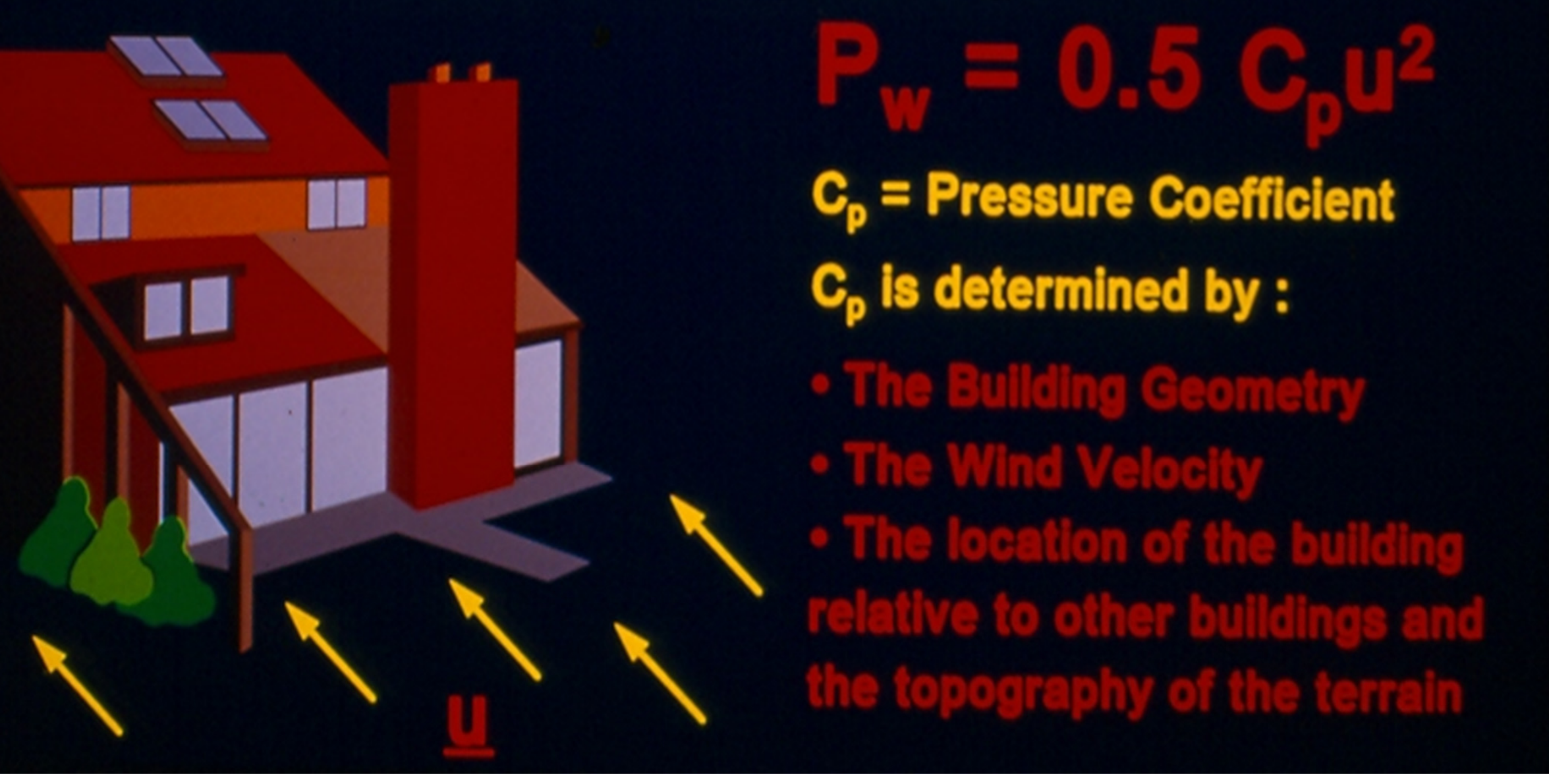




\section{PASSIVE COOLING}

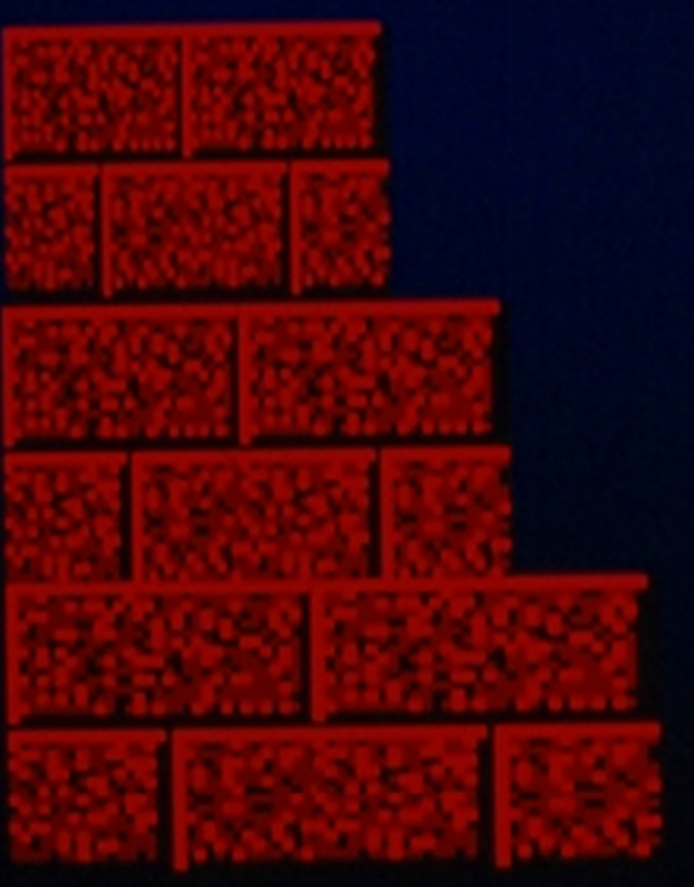

The term Thermal mass describes the ability of ordinary building materials to store heat. In general, the heavier the material the more heat it will store. In summer the thermal mass soaks up the excess heat that enters through the building fabric reducing thus the peak indoor temperatures.

During the night, the heat is slowly released to passing cool breezes that are moving through the building. 
OTHzind Liss - 2

The optimum design of thermal mass should be considered in conjuction with the heating and cooling performance of the building.

The occupation schedule of the building , the use or not of heating and cooling systems as well as the control of the climatic devices are the parameters influencing and determining the optimum level and placing of the thermal mass. 


\section{NATURAL VENTILATION}
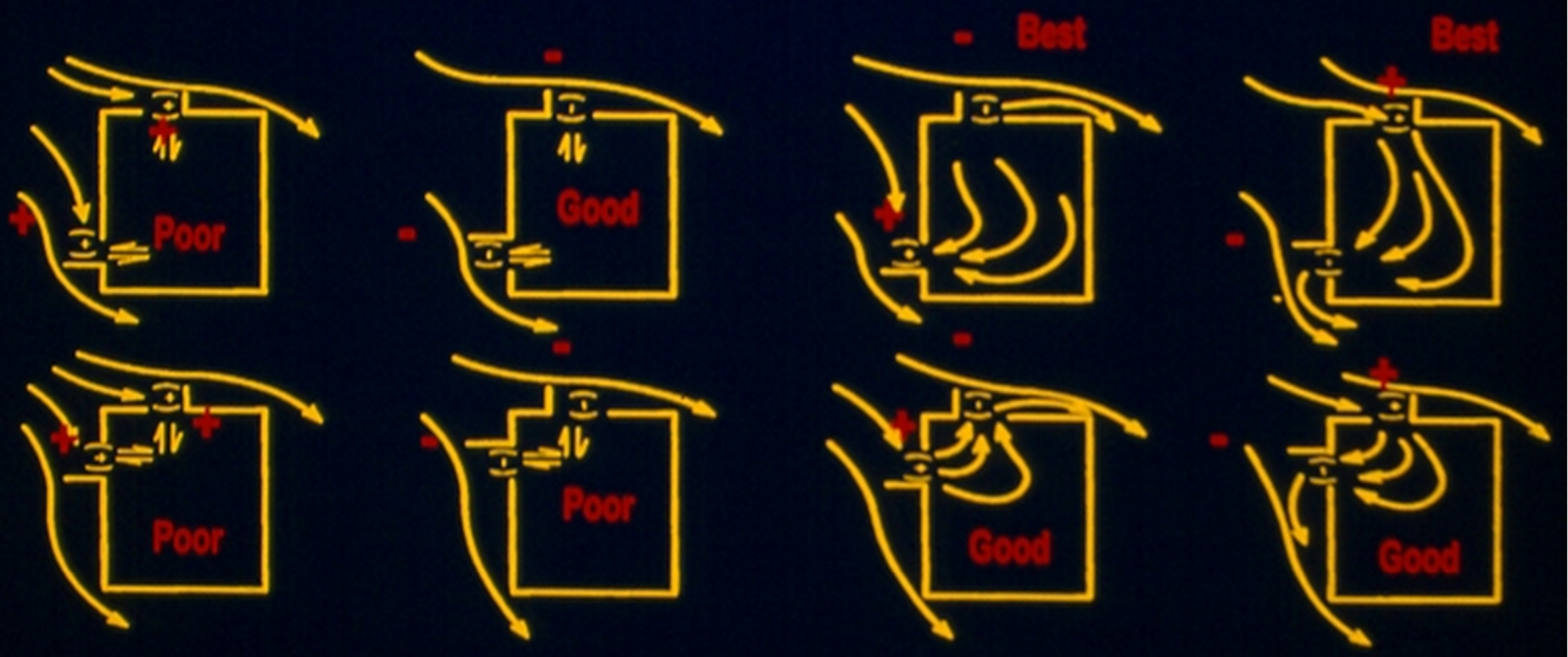

Apertures on Adjacent Wall : Expected Ventilation Results for several wing wall configurations 


\section{NATURAL VENTILATION}

\section{- GEILING FANS}

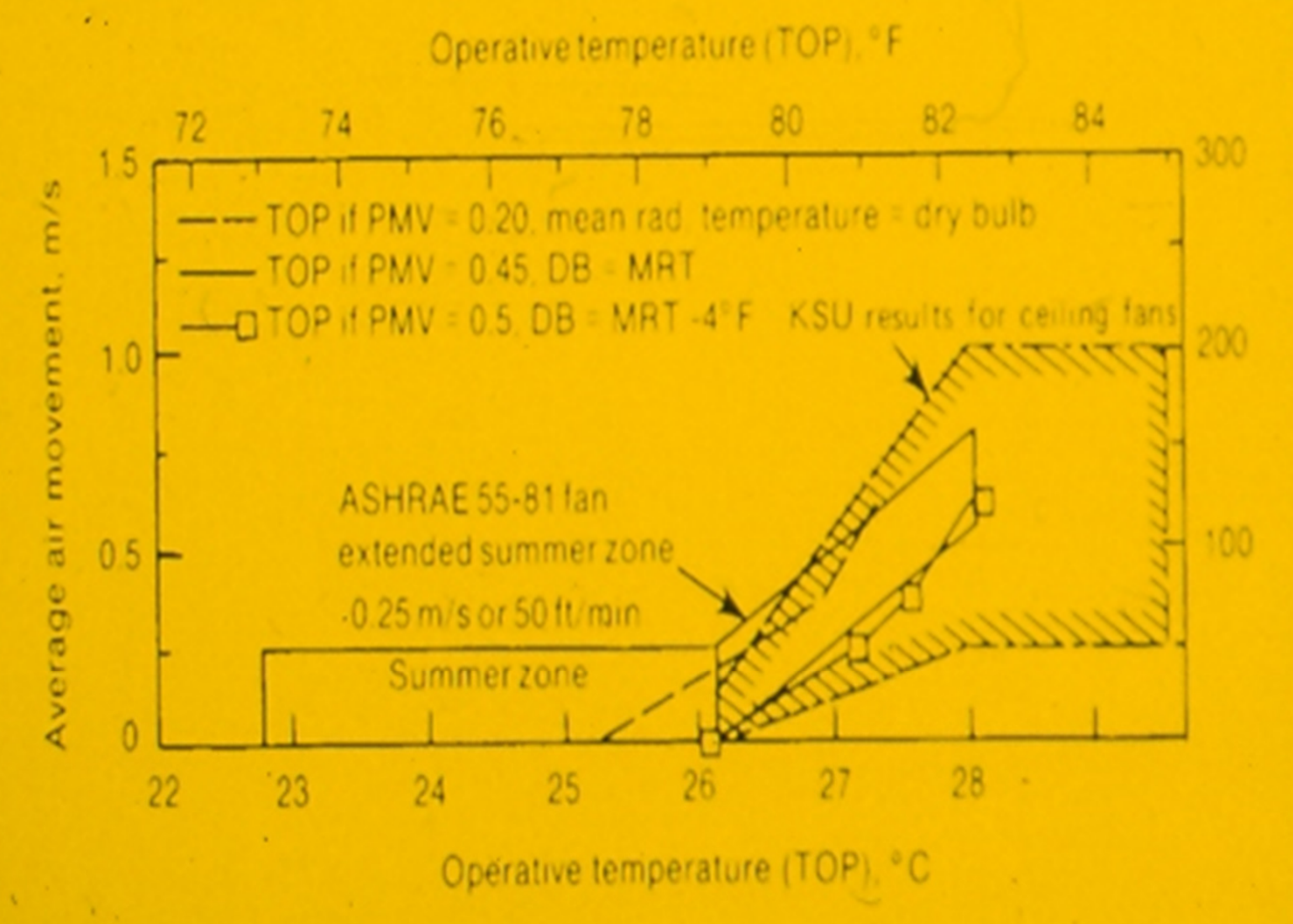

Dxperiments show that air motion induced by celling fans can increase the preferred temperature to $29 \mathrm{C}$ at $50 \%$ relative humidity. 


\section{NATURAL VENTILATION}

\section{- NIGHT VENTILATION}

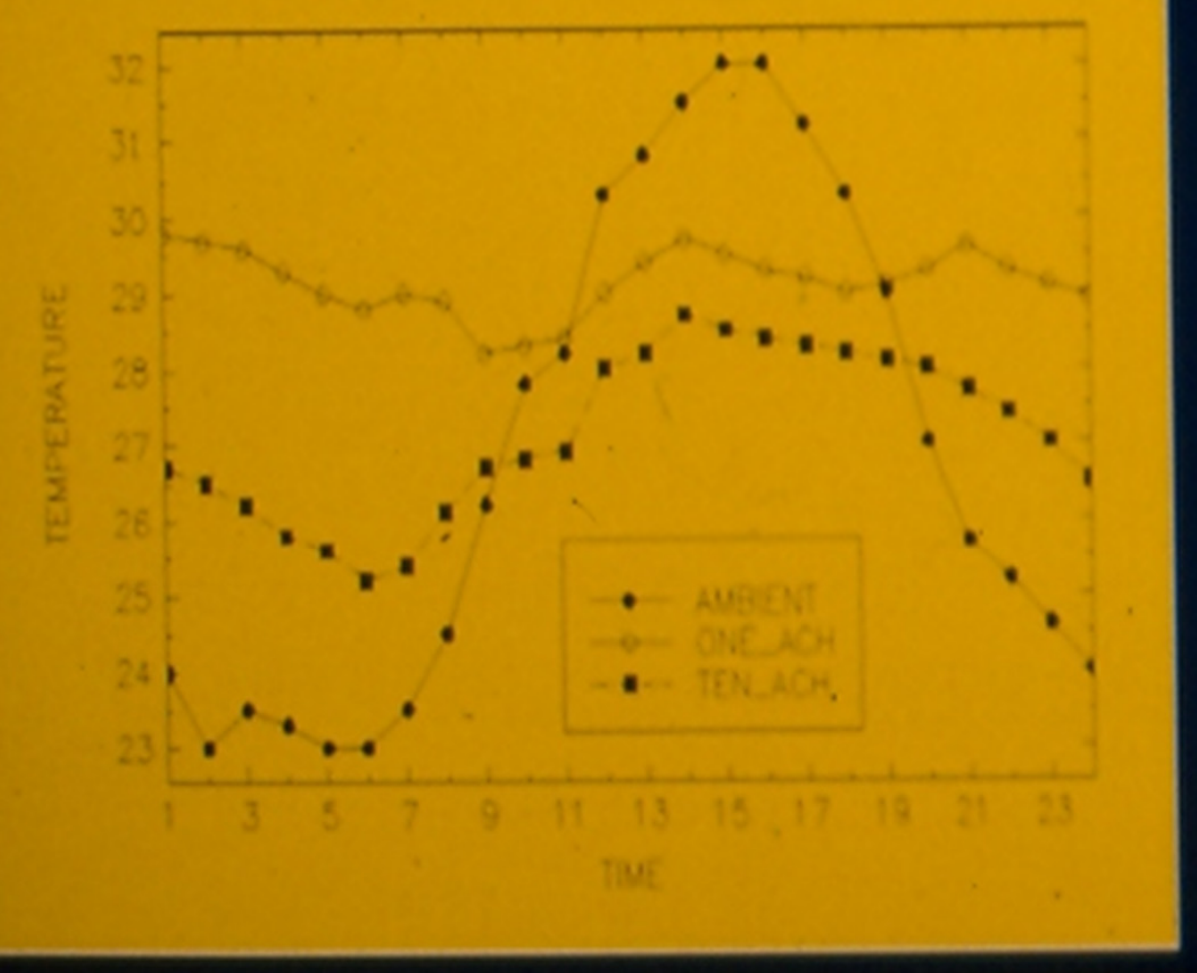

Ambient temperature during night is low. Girsulation of the outdoor air inside the bulliting cools the building's mass and decreases the peak indoor temperatures during the day period. Experiments show that it is possible to decrease the maximum daily temperature of the building by 1 to $2 \mathrm{C}$. 


\section{GROUND COOLING}

\section{- DEFINITIONS}

b

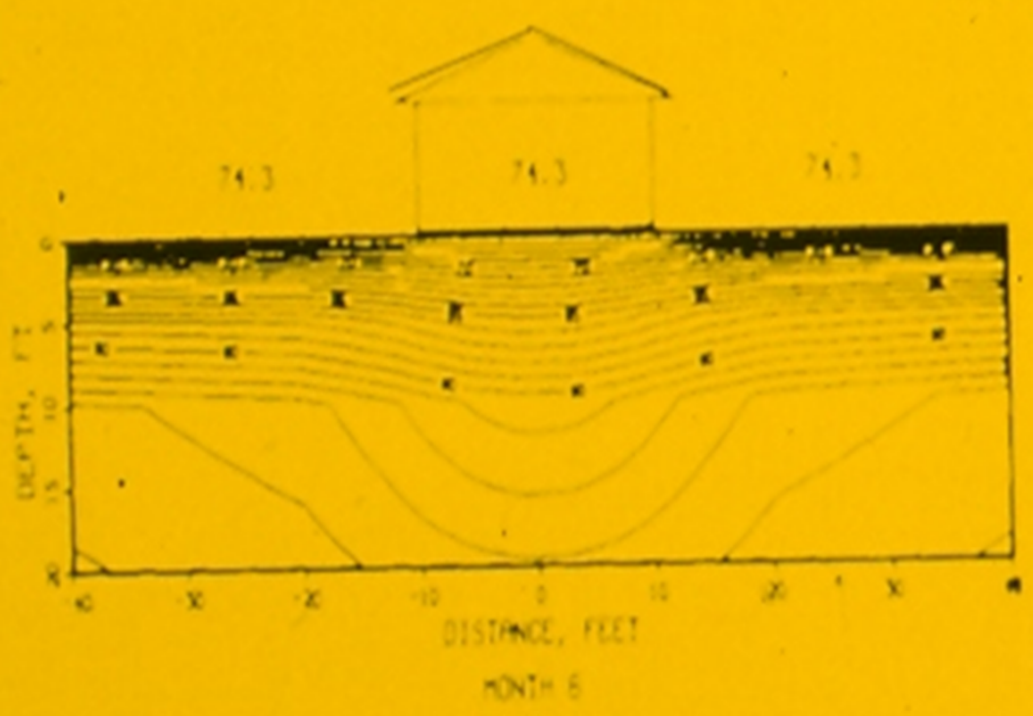
During the summer the soll is considerably lower than the ambient temperature. Therefore, ground ofiers an important source for the dissipation of the buildings excess heat. There are two strategies for the use of the ground:

1. Direct Earth Contact Cooling 2. Buried Pipes. 


\section{GROUND COOLING}

- THE CROUND TEMPERATURE

$T_{z, t}=T_{m}-A_{s} \exp \left[-z(\pi / 365 a)^{0.5]} \cos \left[2 \pi / 365\left[t-t_{0}-z / 2(365 / \pi a)^{0.5}\right]\right]\right.$

Assuming a homogeneous soi

of constant themal difisivivity,

á, the ground temperature at

any depth $z$ and time tis given

by the above expression where

Tm and As are the mean annual

and the amplitute of the ground

temperature 


\section{GROUND COOLING}

- PERRORMANCE OF BURIED PIPES

Temperature

31 Dayys of July

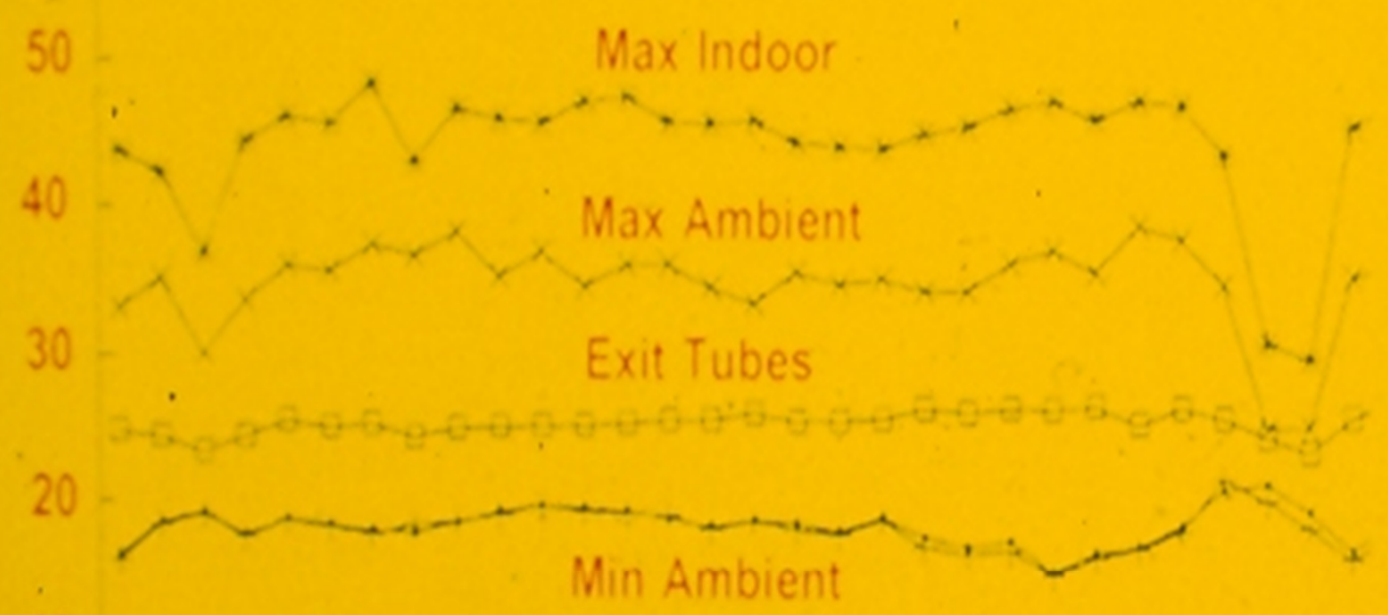

10

Days

The performance of the

buried pipes is a

function of the inlet air

temperature, the

ground temperature,

the thermal

characteristics of the

pipes and soll as well as

of the air velocity, the

pipe dimension and the

nines denth. 


\section{GROUND COOLING}

- PERRORMANCE OF BURIED PIPES

Temperature

31 Dayys of July

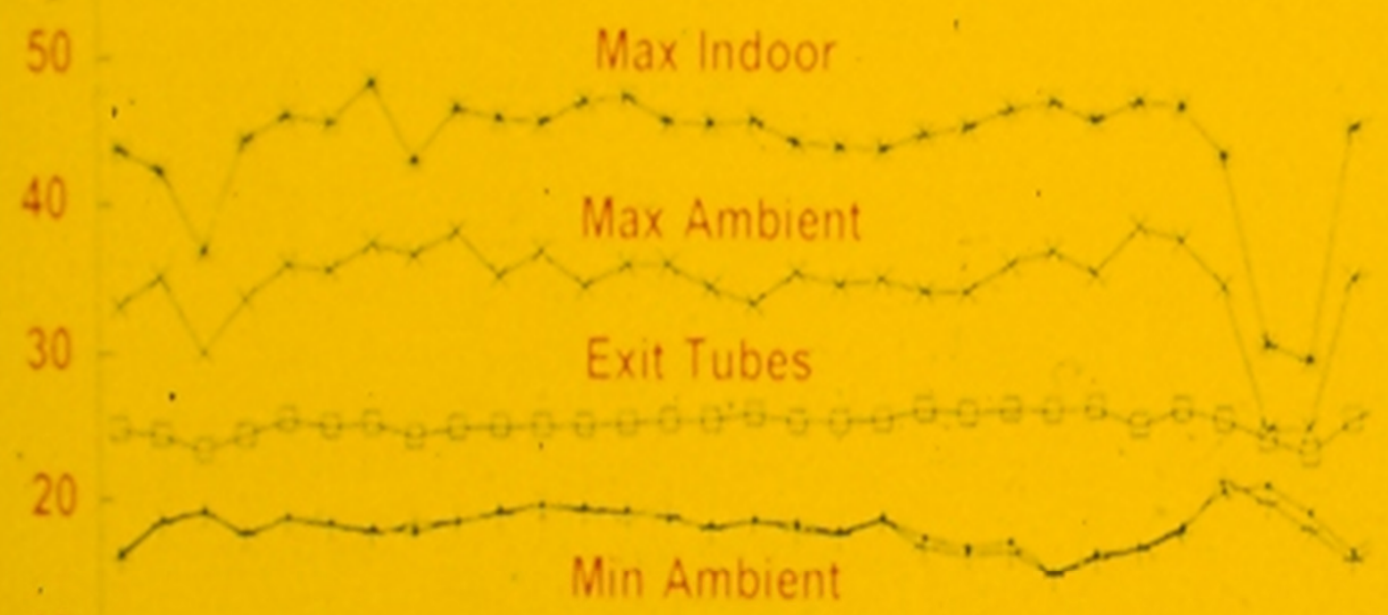

10

Days

The performance of the

buried pipes is a

function of the inlet air

temperature, the

ground temperature,

the thermal

characteristics of the

pipes and soll as well as

of the air velocity, the

pipe dimension and the

nines denth. 


\section{EVAPORATIVE COOLING}

\section{- DEFINITIONS}

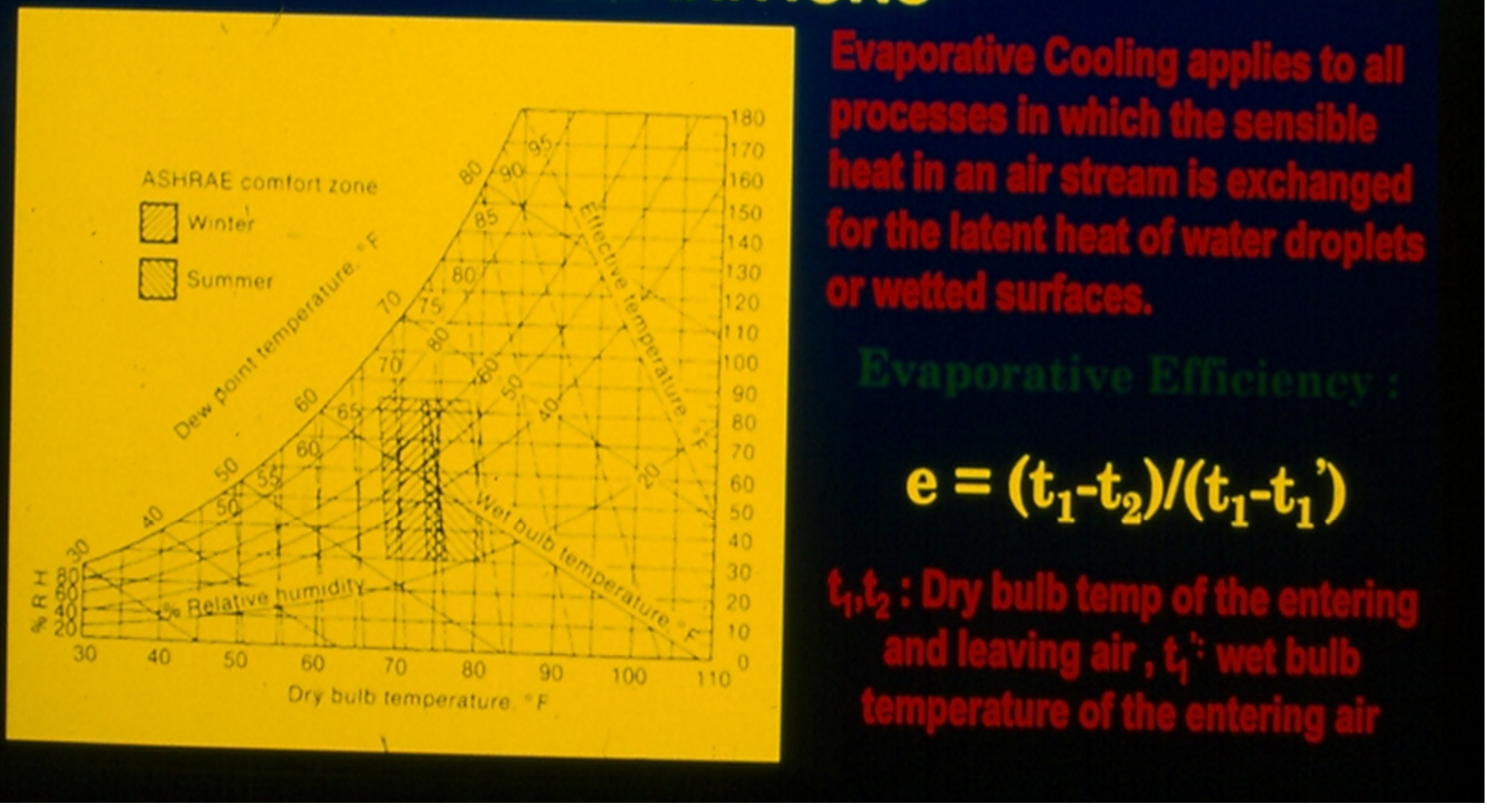




\section{EVAPORATIVE COOLING}

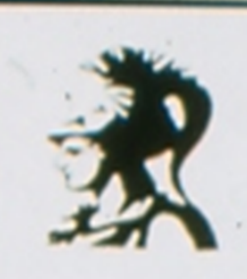

- DIREGT EVAPORATIVE COOLING PROCESSES

$$
{ }_{0}^{\circ} 0_{0}^{\circ} 0_{0}^{\circ} \Rightarrow
$$

$T \beta, \oplus \beta$
10,00

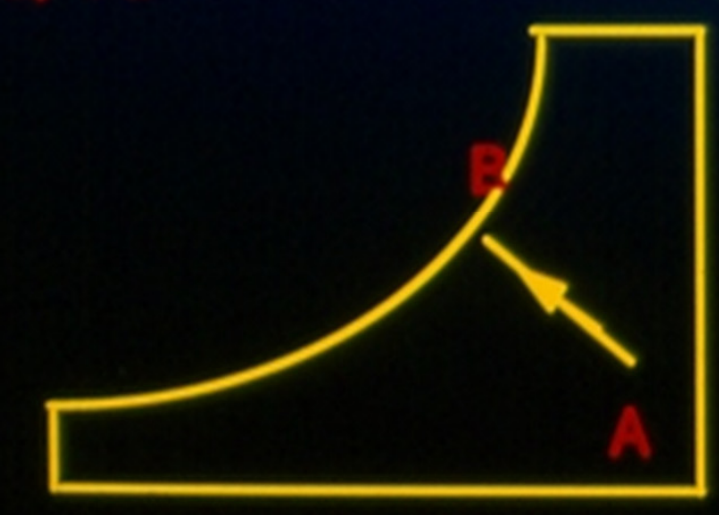

Constant Enthaloy Lino
When the alr stream comes into direot contaot with liquid water , the cooling equipment is characterized as DIi FGT. Direot Evaporation is characterlzed by a dlsplacement along a

$A B$. Thus, the decrease in the dry bulb temperature is accompanied by an increase in the molature content of the alr. 


\section{EVAPORATIVE COOLING}

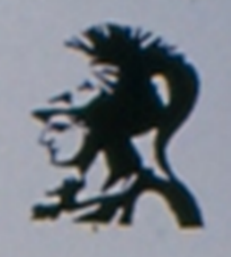

- DIRECT EVAPORATIVE COOLING , (DEC)

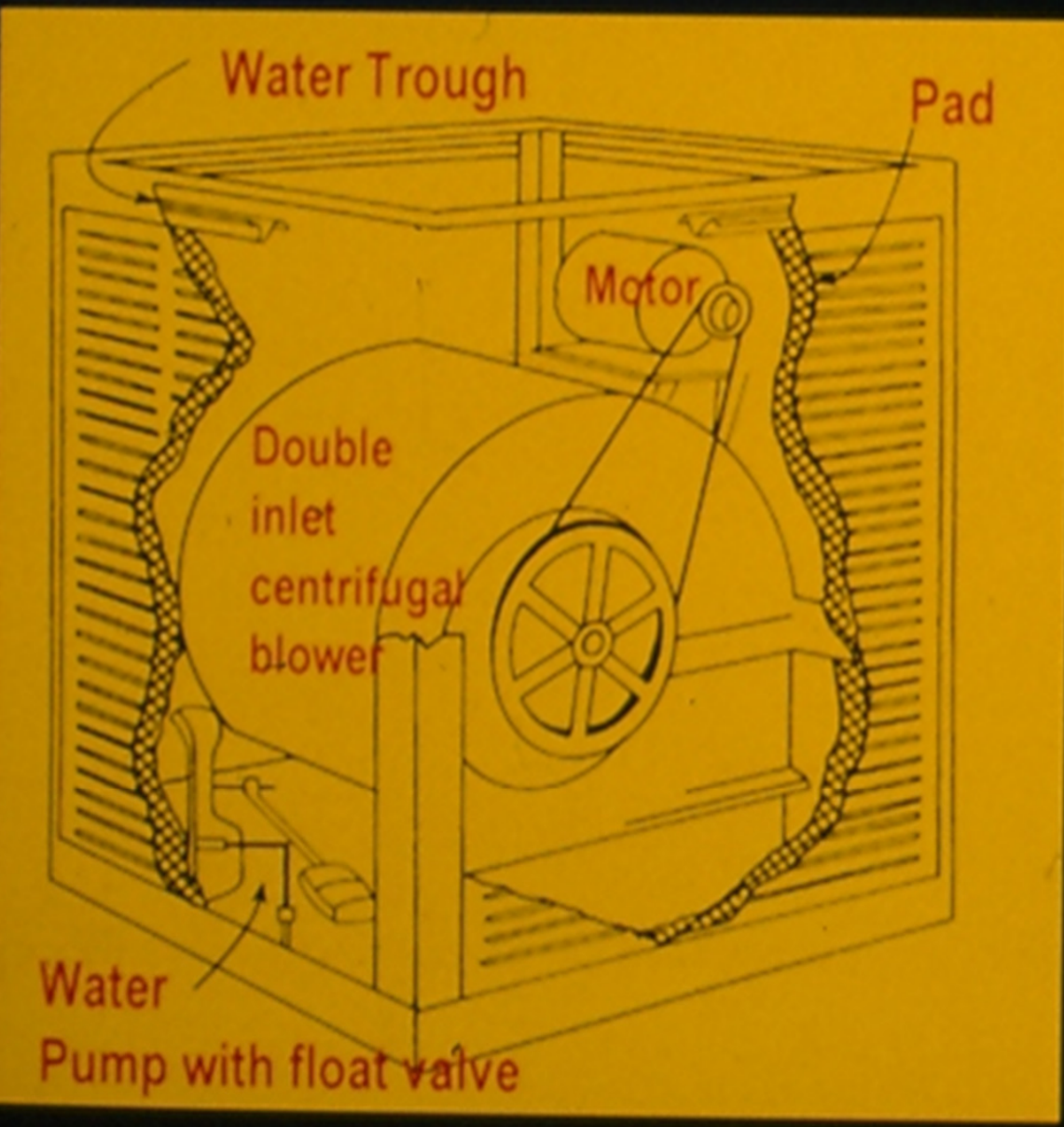

In a direot evaporative cooler water is supplied to a small reservoir and then flows through fibrous pads. The air temperature is reduced by about $70-80 \%$ of the difierence between the dry, D.B.T, and the wet bulb, W.3, temperature of the air. The olimatic criterion for the applioability of D.E.C is the ambient W.B.T. and a large difierence between D.B.T and 


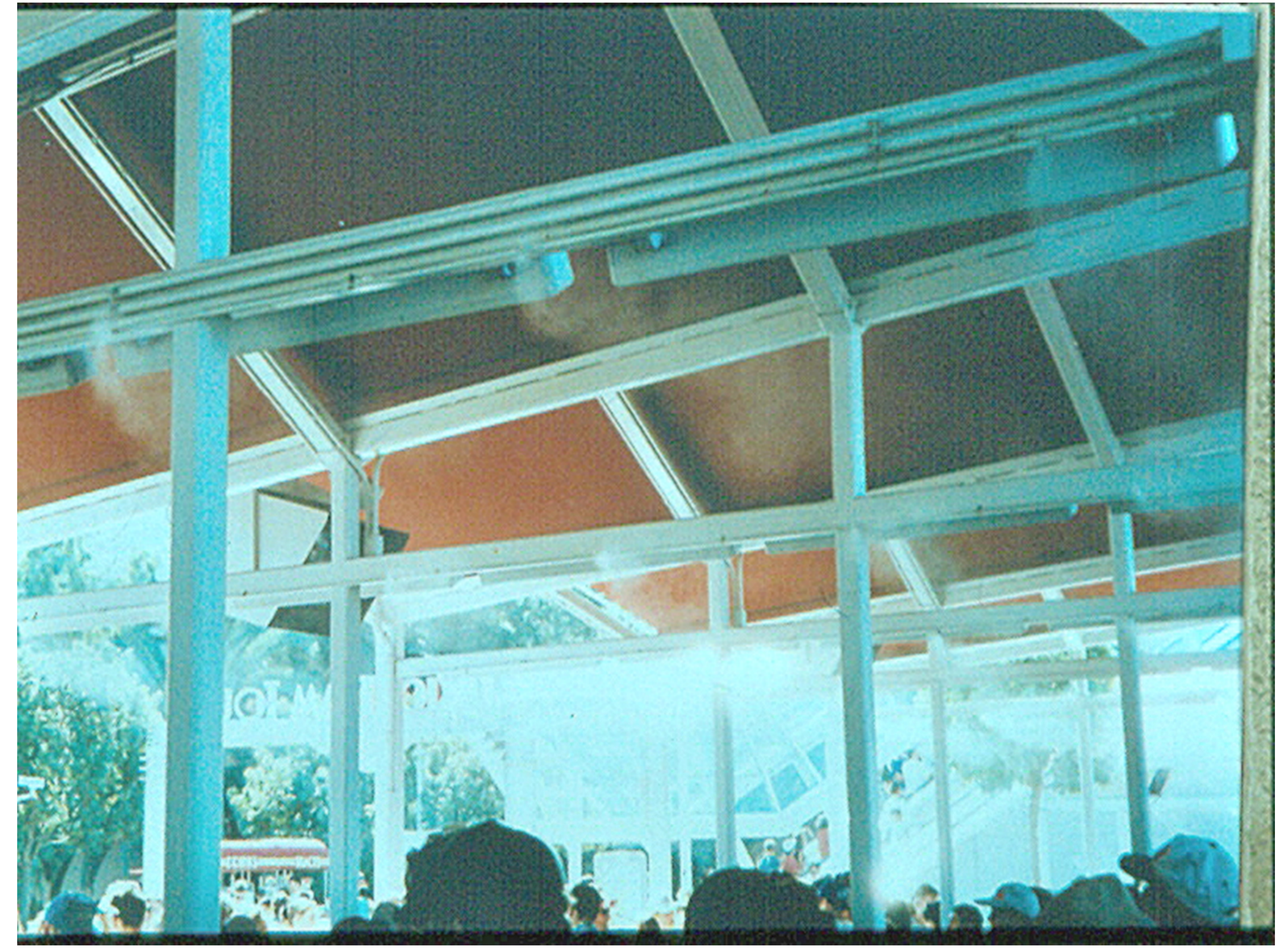




\section{EVAPORATIVE COOLING}

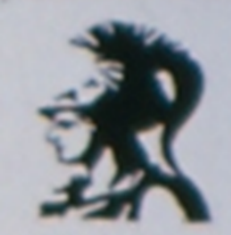

- CLIMATIC APPLICABILITY LIMITS OF EVAPORATIVE
COOLING

DIIRIET : Only Where and When the maximum Wet Bulb Temperature in summer is about $22 \mathrm{C}$ and the maximum dry bulb temperature is about $42 \mathrm{C}$.

II TDIIRTET : As the indoor humidity is not elevated by indirect evaporative cooling, it is possible to apply in places where the maximum wet bulb temperature is 24 $\mathrm{C}$ and the maximum dry bulb temperature is $44 \mathrm{C}$. 


\section{EVAPORATIVE COOLING}

- INDIRECT EVAPORATIVE COOLING PROCESSES

When the air is cooled without

10100

$4,0^{\circ}, 0^{\circ}$

$T \beta, \Phi \beta$

$\Rightarrow$ (a, 00

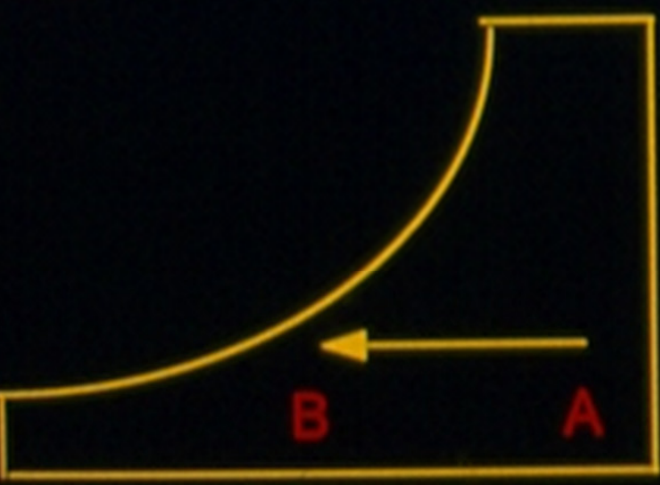

Constant Moisture Content Lino addition of moisture by passing through a heat exchanger which uses a secondary stream of air or water , the cooling equipment is characterized as INDIiEECT. Indirect Evaporation is characterized by a displacement along a moisture content line AB. . Thus, the dry bulb temperature is decreased without increase of the moisture content of the air. 


\section{EVAPORATIVE COOLING}

- INDIRECT EVAPORATIVE COOLING , (IEC)

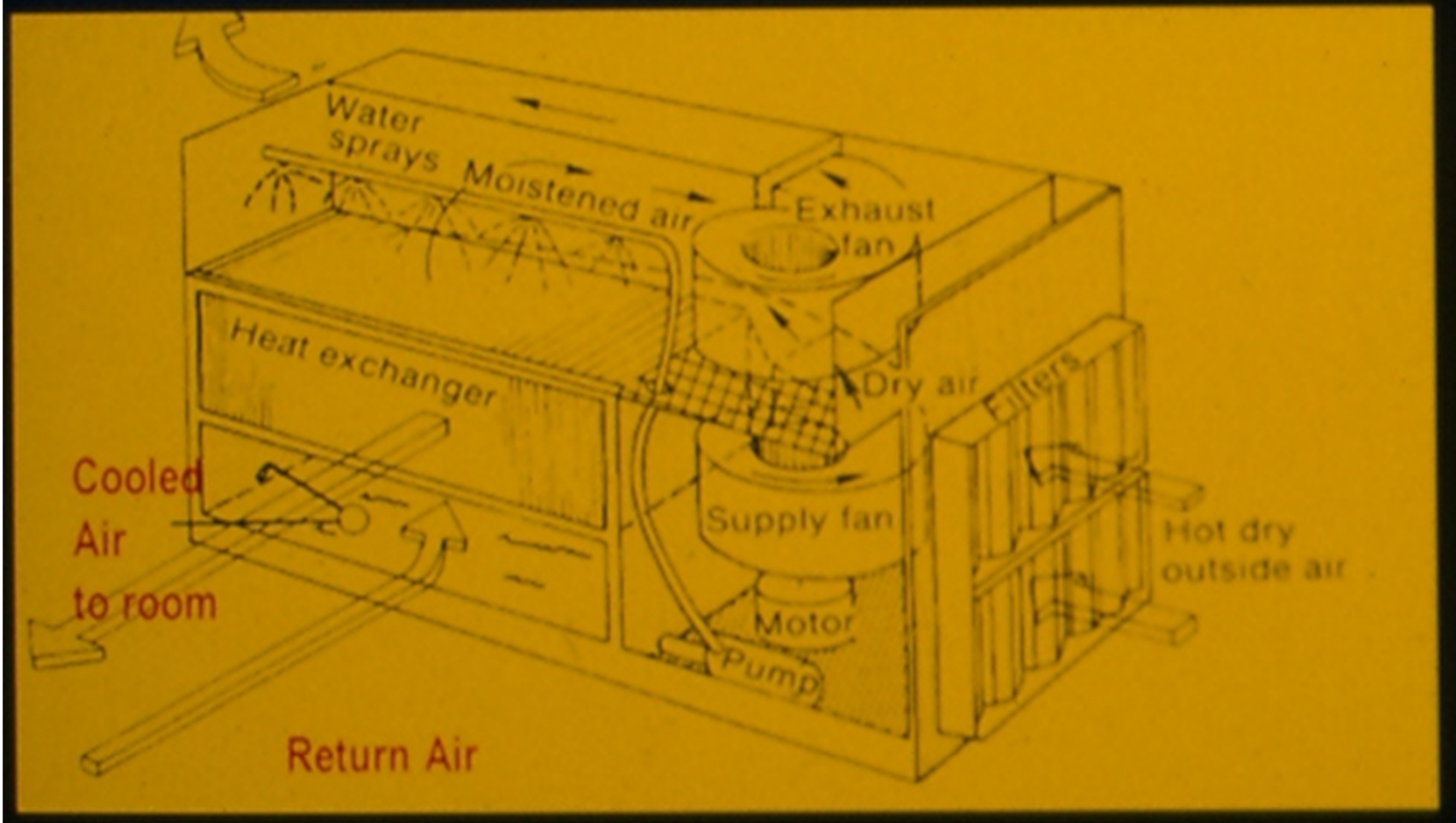

It is based on the use

of a heat exchanger

where the indoor

ventilated air passes

through the primary

circuit where

evaporation occurs

while the fresh air

passes through the

secondary circuil

Energy Savings of up to 60 percent compared to A/C may be achieved in hot dry regions 


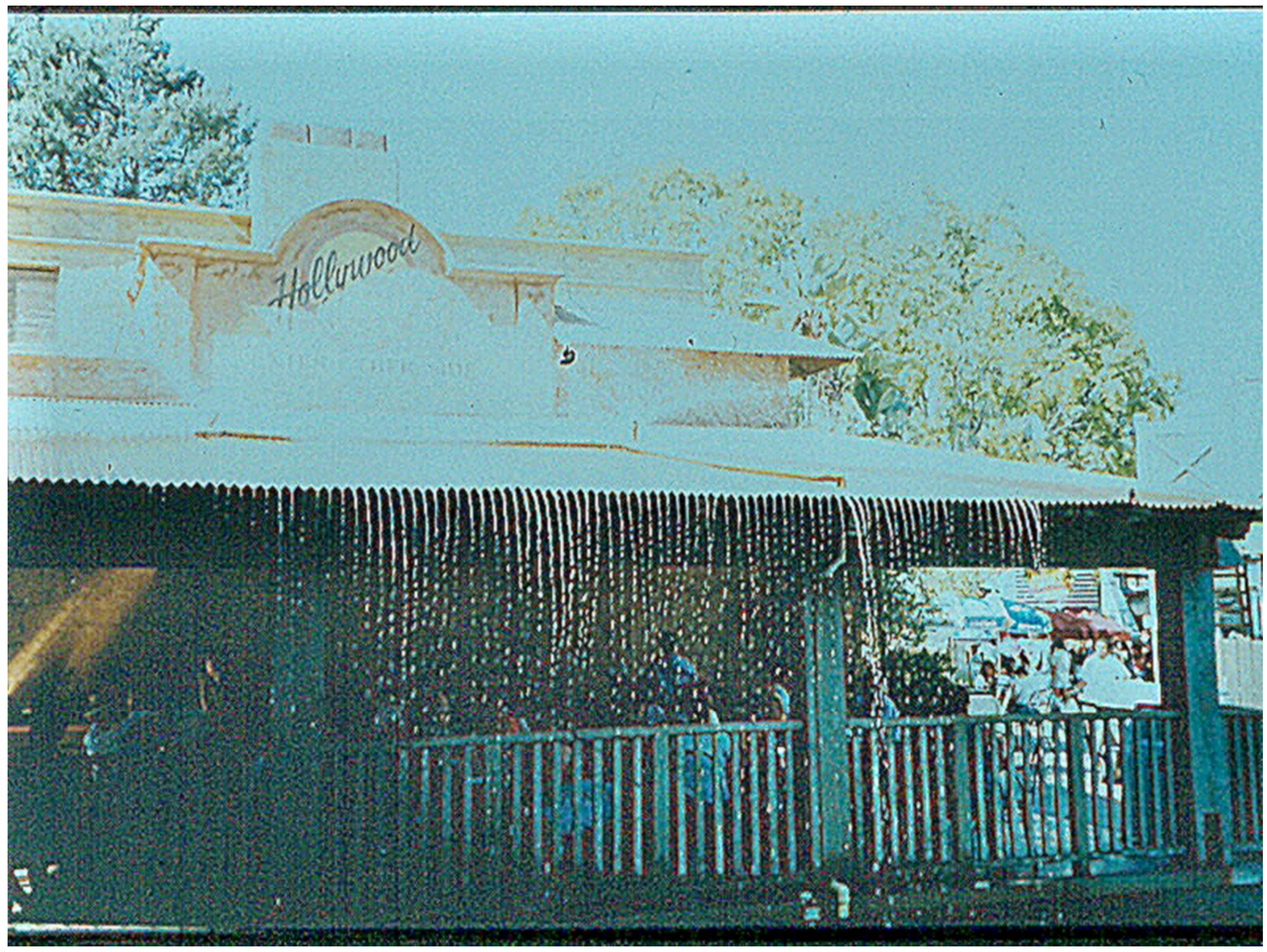

